\title{
Outcomes Of Chimney Technique For Aortic Arch Diseases: A Single-Center Experience With 226 Cases
}

This article was published in the following Dove Press journal: Clinical Interventions in Aging

Wenhui Huang, $1,2, *$ Huanyu Ding, (D) 2,* Minchun Jiang, ${ }^{3, *}$ Yuan Liu, ${ }^{2}$ Cheng Huang, ${ }^{2}$ Xinyue Yang, ${ }^{2,4,5}$ Ruixin Fan, ${ }^{6}$ Jianfang Luo, ${ }^{2,4,5}$ Zhisheng Jiang'

'Institute of Cardiovascular Disease and Key Laboratory for Arteriosclerology of Hunan Province, Hengyang Medical School, University of South China, Hengyang, Hunan, People's Republic of China; ${ }^{2}$ Department of Cardiology, Vascular Center, Guangdong

Cardiovascular Institute, Guangdong Provincial Key Laboratory of Coronary Heart Disease Prevention, Guangdong Provincial People's Hospital, Guangdong Academy of Medical Sciences, Guangzhou, Guangdong, People's Republic of China; ${ }^{3}$ School of Biomedical Sciences, The Chinese University of Hong Kong, Sha Tin, Hong Kong, People's Republic of China;

${ }^{4}$ Guangdong Provincial People's Hospital affiliated to South China University of Technology, Guangzhou, Guangdong, People's Republic of China; ${ }^{5}$ School of Medicine, South China University of Technology, Guangzhou, Guangdong, People's Republic of China; ${ }^{6}$ Department of Cardiovascular Surgery, Vascular Center, Guangdong Cardiovascular Institute, Guangdong Provincial Key Laboratory of Coronary Heart Disease Prevention, Guangdong Provincial People's Hospital, Guangdong Academy of Medical Sciences, Guangzhou, Guangdong, People's Republic of China

*These authors contributed equally to this work
Correspondence: Zhisheng Jiang Institute of Cardiovascular Disease and Key Laboratory for Arteriosclerology of Hunan Province, Hengyang Medical School, University of South China, Hengyang, Hunan, People's Republic of China

Email drzhishengjiang@I26.com
Purpose: The goal of present study is to document our single-center experience with chimney technique for aortic arch diseases.

Patients and methods: From August 2012 to October 2017, 226 patients (mean age 54 \pm 12 years; 197 men) with aortic arch diseases underwent thoracic endovascular aortic repair combined with chimney stents. The aortic stent-grafts were deployed in zone $0(n=22)$, zone $1(n=13)$, or zone $2(n=191)$.

Results: The technical success rate was $84 \%$ (189/226) and immediate type Ia endoleak (ELIa) happened in 37 (16\%) patients. The 30-day mortality and morbidity rates were 2\% (4/ 226) and 4\% (8/226), respectively. Major adverse events include four major strokes, three spinal cord ischemia and one aortic rupture in the early-term. The clinical and imaging follow-up rates were $98 \%(218 / 222)$ and $78 \%$ (173/222), respectively. The average lengths of clinical and imaging follow-up were $22 \pm 16$ months and $20 \pm 15$ months, respectively. Chimney stent obstructions in left subclavian arteries were recorded in six (3\%) patients. During follow-up, five patients died (2\%) and two major strokes occurred (1\%). One patient $(0.5 \%)$ underwent reintervention.

Conclusion: The current study documented that the chimney technique is effective and safe for treating aortic arch diseases in different aortic zones. Cautions are needed to assess the permanency of chimney stent and to reduce the immediate ELIa rate.

Keywords: aortic arch disease, chimney, endoleak, thoracic endovascular aortic repair

\section{Introduction}

Thoracic endovascular aortic repair (TEVAR) is regarded as a valued alternative for patients with aneurysms and dissection of the descending thoracic aorta thanks to its less invasive characteristics. ${ }^{1}$ Due to an insufficient proximal landing zone, endovascular management of lesions comprising the aortic arch is perplexing.

Several strategies, for instance, chimney technique, ${ }^{2-4}$ hybrid technique, ${ }^{5}$ fenestrated or branched stent-grafts, ${ }^{6,7}$ have been reported as options to preserve the supra-aortic branches, each with its own advantages and disadvantages. The hybrid technique consists of various types of supra-aortic vessel debranching maneuvers. For patients with zone 0 pathologies, total aortic arch debranching with sternotomy is required. The clinical outcome of hybrid technique has large variation, with mortality and morbidity rates range from $2.0 \%$ to $23.7 \%$, and $0.8 \%$ to $18.8 \%$, respectively. ${ }^{8,9}$ While some researches have reported favorable results with using fenestrated or branched stent-grafts in aortic arch diseases, these methodologies had limited applicability due to the morphological variety of the aortic arch, requiring tailor made and patient-specific devices. Furthermore, the processes are 
complicated, time-consuming, and frequently inappropriate during emergency circumstances. ${ }^{10}$

An alternative method of perfusing the supra-aortic vessels is the chimney technique that was first employed in the aortic arch to salvage the inadvertently covered left subclavian artery (LSA) ${ }^{11}$ In recent years, the use of the chimney technique has rapidly augmented for the management of aortic arch diseases. Nonetheless, the long-term effectiveness remains to be fully evaluated. ${ }^{12-15}$

The purpose of this retrospective study is to describe our experience using the chimney technique for aortic arch diseases which focuses on the early- and mid-term consequences in a large cohort of patients $(n=226)$.

\section{Materials And Methods}

\section{Study Participants}

From August 2012 to October 2017, 226 consecutive patients (mean age $54 \pm 12$ years, range 17-83 years; 197 men and 29 women) with aortic arch diseases undertook TEVAR along with aortic arch chimney stents at Guangdong Provincial People's Hospital in China. The indications for these chimney stents included accidental coverage of a supra-aortic vessel or a proximal landing zone $<1.5 \mathrm{~cm}$. All participants underwent computed tomography angiography (CTA) and were accessed by a committee of cardiologists, cardiovascular surgeons, endovascular surgeons, radiologists as well as anesthesiologists. Demographics, medical history, comorbidities, imaging features, operation parameters, as well as follow-up records were acquired and investigated.

\section{Ethics}

The study was a retrospective study using the medical record. The Health Informatics Center anonymize all related data and oversee the study protocol. In the process of the study, researchers covering all data confidentiality and compliance with the Declaration of Helsinki. Thus, patient consent to review their medical records was not required in this retrospective study. The Ethics Committee of the Guangdong Provincial People's Hospital approved this study (No. 2017300H).

\section{Procedures}

For patients with zone 0 pathologies, preliminary surgical supra-aortic vessel debranching under general anesthesia was necessary. They received endovascular treatment after recovering from general anesthesia and removal of the tracheal intubation. For patients with lesions in Zone 1 or
Zone 2, procedure was performed in the cardiac catheterization room under local anesthesia. In emergency cases or patients with symptomatic pain, analgesics such as fentanyl and morphine were used.

All aortic stent-grafts were retrogradely installed through the percutaneous femoral approach with the preclosing technique. ${ }^{16}$ Rapid ventricular pacing technique was utilized in the placement of aortic stent-grafts. ${ }^{17}$ The degree of aortic stent-graft oversize depended on the pathologies and whether chimney stents were implanted or not. At our hospital, for patients with chimney stent, the diameters of aortic stent-grafts were usually oversized by $10-15 \%$ in dissection and $15-20 \%$ in aneurysm. But for patients without chimney stent, the diameters of aortic stent-grafts were usually reduced to $5-10 \%$ in dissection and $10-15 \%$ in aneurysm. Additionally, for the cases of trauma, the oversizing rate was $5-10 \%$.

For the chimney stent in innominate artery (IA), a sheath was led into the right brachial access. For the bare chimney stent in LSA, left radial access was used. While for the cover chimney stent in LSA, we would use the left brachial artery. By the radial or brachial access, a stiff guide wire was introduced into the ascending thoracic aorta. Once the aortic stent-graft was inserted into the aortic arch, the chimney stent was transported into the LSA or IA via the arterial sheath. Under controlled hypotension (systolic blood pressure $<90 \mathrm{mmHg}$ ), the aortic stent-graft was first installed and the chimney stent was installed as quickly as possible. The maneuver in the chimney technique in left common carotid artery (LCCA) or right common carotid artery (RCCA) was equivalent to that in the LSA. The percutaneous access of the LCCA or RCCA was accomplished.

Angiography was done to assess the locations of the stent-graft and the chimney stent, along with the immediate type Ia endoleak (ELIa). Postoperatively, patients received clopidogrel $75 \mathrm{mg}$ per day for 1 month in addition to aspirin $100 \mathrm{mg}$ per day for an indefinite period.

\section{Follow-Up}

Patients were routinely scheduled for follow-up. Survival assessment was completed through outpatient visits or telephonic interviews. Contrast CTA was done to assess the aortic morphology as well as patency of the chimney or bypass. For patients with ELIa, whose aortic growth $>5$ $\mathrm{mm} /$ year or aortic diameter $>50 \mathrm{~mm}$, CTA was done at 1 , 3,6 , and 12 months and annually thereafter. In patients who did not have the above conditions, CTA was done at 3 
months and then yearly. After 3 years of follow-up, the situation is considered stable and the interval can be protracted to 2-3 years. If the patient has new signs of symptoms or adverse events, an additional CTA exam is obtained. Even though CTA was done in a different hospital, the images were assessed by a minimum of two doctors who participated in the study.

\section{Definitions}

Complicated TBAD was defined as signs of rupture (haemothorax, accumulative periaortic, and/or mediastinal haematoma), malperfusion, uncontrolled hypertension in spite of appropriate medicines, constant or recurring pain, and early aortic expansion. ${ }^{1}$ Ishimaru zones classification was employed to explain the sites of attachment. ${ }^{18}$ Primary technical success meant the effective introduction and deployment of the device, without conversion to open repair, death within $24 \mathrm{hrs,} \mathrm{type} \mathrm{I} \mathrm{or} \mathrm{III} \mathrm{endoleaks,} \mathrm{or}$ graft impediment. Spinal cord ischemia was graded as stated by the reporting criteria for TEVAR. ${ }^{19}$ The main adverse events (AEs) comprised all-cause death, aortic rupture, reintervention, stroke and spinal cord ischemia.

\section{Statistical Analysis}

Categorical data were presented as the counts (percentage) and continuous data were described as the mean \pm standard deviation. The Kaplan-Meier analysis was employed to assess the freedom from all-cause death, aortic-specific death as well as main AEs. Log-rank tests were utilized to distinguish among the Kaplan-Meier curves. All statistical assessments were two-sided and the $\mathrm{P}$ values $<0.05$ were considered statistically significant. SPSS (Version 22.0, IBM Corp, Armonk, NY, USA) was utilized for analysis.

\section{Results}

\section{Demographics, Coexisting Medical Condition And Indications For TEVAR}

From August 2012 to October 2017, 226 patients with aortic arch diseases experienced TEVAR in combination with chimney stents in our center. Most of the patients were male $(87 \% ; n=197)$, and the mean age was $54 \pm 12$ years (range, 17-83 years). Hypertension, the utmost usual simultaneous clinical condition, was confirmed in 178 (79\%) patients. Smoking was found in 70 (31\%) patients. Additional details of comorbidities and the indications for TEVAR with aortic arch chimney stents are presented in Table 1.

\section{Details Of The Surgery}

TEVAR was done in emergent situations in 4 patients with aortic rupture and in 6 acute TBAD patients with intestinal ischemia or lower extremity ischemia. The aortic stentgrafts were positioned proximally in zone $0(\mathrm{n}=22,10 \%)$, zone $1(\mathrm{n}=13,6 \%)$, or zone $2(\mathrm{n}=191,84 \%)$ according to the Ishimaru classification. Seventeen patients received two aortic stent-grafts and one patient received three aortic stent-grafts. 230 chimney stents were installed in 226 patients, where double chimney technique (LCCA + LSA) was done in four cases. The majority $(\mathrm{n}=193$, $84 \%)$ chimney stents were bare stents, and $178(77 \%)$ were self-expandable stents. The chimney graft was installed as a bailout to restructure the LCCA in 6 patients with partial unintended coverage of the LCCA during TEVAR (Figure 1). For zone 1 patients who received a single LCCA chimney stent, occluded LSA was not a routine procedure in our center. Details of the procedures are presented in Table 2.

\section{Early-Term Outcomes}

The average duration of postoperative hospital stay was 8 \pm 5 days (range, 1-44 days). The technical success rate was $84 \%(189 / 226)$. In the present study, immediate ELIa happened in $37(16 \%)$ patients. Given that the ELIa had low flow and most of the immediate ELIa would diminish or disappear during the follow-up, these immediate ELIa were treated conservatively with close surveillance. No complications due to anesthesia or supra-aorta bypass occurred in zone 0 patients.

The 30 -day mortality rate was $2 \%(4 / 226)$. The causes for deaths were ventricular fibrillation in one case, aortic rupture in one case, and major stroke in two cases. A total of four major strokes were documented, including the two that ultimately led to deaths in hospital. The other two patients gradually recovered at discharge. Spinal cord ischemia happened in three cases, out of which one was temporary (Grade 2) and the other two were everlasting (Grade 3a). Reintervention was not documented. Hence, the main AEs rate was 4\% (9/226) during the early-term.

\section{Follow-Up Outcomes}

98\% (218/222) patients were effectively followed up by hospital visits or telephonic interviews to evaluate survival. The average period of medical follow-up was $22 \pm 16$ months (range 1-65 months). In the course of the followup, deaths were reported in five patients. Three of them 
Table I Demographic Characteristics, Coexisting Medical Conditions And Indications For TEVAR

\begin{tabular}{|c|c|c|c|c|}
\hline & Zone $0(\mathrm{~N}=22)$ & Zone I $(\mathrm{N}=13)$ & Zone $2(\mathrm{~N}=|9|)$ & Total $(N=226)$ Or Mean \pm SD \\
\hline \multicolumn{5}{|l|}{ Demographic characteristics } \\
\hline Age & $54 \pm 13$ & $56 \pm 13$ & $54 \pm 12$ & $54 \pm 12$ \\
\hline Male & 22 & 12 & 163 & 197 \\
\hline \multicolumn{5}{|l|}{ Coexisting medical conditions } \\
\hline Hypertension & 14 & 10 & 154 & 178 \\
\hline Coronary artery disease & 6 & 2 & 30 & 38 \\
\hline Diabetes mellitus & 2 & I & 16 & 19 \\
\hline Hyperlipidemia & 9 & 5 & 55 & 69 \\
\hline Stroke & 2 & 0 & 9 & 11 \\
\hline Chronic obstructive pulmonary disease & 2 & 0 & 4 & 6 \\
\hline Chronic kidney disease & 2 & 0 & 20 & 22 \\
\hline Acute kidney injury & 3 & 1 & 9 & 13 \\
\hline Peripheral arterial disease & 1 & 0 & 10 & 11 \\
\hline Abdominal Aortic Aneurysm & 2 & 0 & 5 & 7 \\
\hline Smoke & 9 & 4 & 57 & 70 \\
\hline Prior aortic surgery & 0 & I & 5 & 6 \\
\hline Traumatic aortic disease & 0 & 0 & 5 & 5 \\
\hline Marfan syndrome & 0 & 1 & I & 2 \\
\hline ARSA & I & 0 & 0 & I \\
\hline Left vertebral artery originates from aortic arch & 0 & 0 & 5 & 5 \\
\hline Common origin of the IA and LCCA & 0 & 0 & 4 & 4 \\
\hline \multicolumn{5}{|l|}{ Indications for TEVAR } \\
\hline TBAD & 10 & 12 & 163 & 185 \\
\hline Acute TBAD & 4 & 6 & 104 & 114 \\
\hline Subacute TBAD & 2 & 5 & 45 & 52 \\
\hline Chronic TBAD & 4 & I & 14 & 19 \\
\hline Aortic arch aneurysm & 9 & 1 & 0 & 10 \\
\hline Aortic arch pseudoaneurysm & 2 & 0 & 0 & 2 \\
\hline Descending thoracic aortic aneurysm & 0 & 0 & 3 & 3 \\
\hline Descending thoracic aortic pseudoaneurysm & 0 & 0 & 8 & 8 \\
\hline Penetrating aortic ulcer & 0 & 0 & 7 & 7 \\
\hline Intramural hematoma & 0 & 0 & 7 & 7 \\
\hline Aortic rupture & I & 0 & 3 & 4 \\
\hline
\end{tabular}

Abbreviations: ARSA, aberrant right subclavicular artery; IA, innominate artery; LCCA, left common carotid artery; TBAD, type B aortic dissection; TEVAR, thoracic endovascular aortic repair.

were due to aortic rupture, one was due to cerebral hemorrhage and the last one was due to rectal cancer. Besides, two patients suffered from stroke. One patient received reintervention due to the distal expansion. The particulars of the clinical outcomes are presented in Table 3.

In our study, imaging follow-up of 49 patients was not done for numerous reasons (e.g. loss of communication, $n=4$; financial reasons, $\mathrm{n}=6$; CTA was accepted in other hospitals and imaging data were not available, $n=31$; patients refused, $n$ $=8$ ). As a result, we had access to follow-up imaging results from only $78 \%(173 / 222)$ patients received CTA to assess aorta morphology as well as the patency of chimney stents or bypasses. The average period of imaging follow-up was 20 \pm 15 months (range 1-64 months). Among these 173 patients, 139 were TBAD, 20 were aneurysms and 14 were other pathologies (penetrating aortic ulcer, intramural hematoma or aortic rupture). There was no substantial change in the maximum aortic diameters among those with and without ELIa $(39.5 \pm 8.0 \mathrm{~mm}$ vs $39.3 \pm 7.1 \mathrm{~mm}, \mathrm{p}=0.902)$. For patients with aneurysms, there were five patients with sac regression, and the maximum diameters of aneurysm decreased from $60.5 \pm$ $5.3 \mathrm{~mm}$ to $57.2 \pm 4.9 \mathrm{~mm}, 91 \%(126 / 139)$ patients with TBAD 


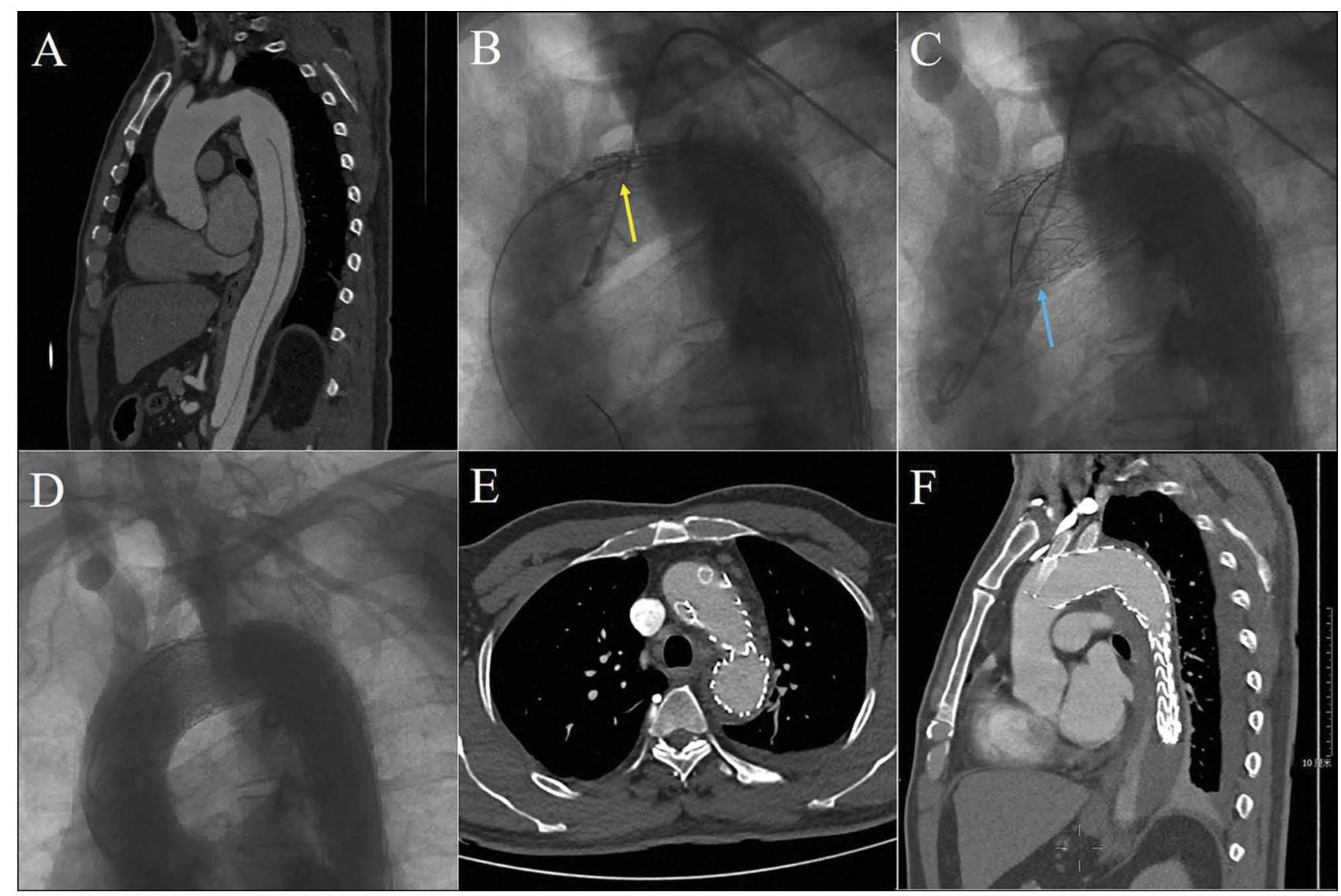

Figure I Chimney stent was deployed as a bailout to reconstruct the LCCA. TBAD was confirmed by preoperative CTA (A). The aortic stent-graft was planned to deploy between LCCA and LSA (yellow arrow) (B), but the ostia of LCCA was partially covered (blue arrow) accidentally (C). Double chimney technique (LCCA + LSA) was conducted (D), and postoperative CTA showed that both chimney stents were patent without endoleak at 6 months follow-up (E and F).

Abbreviations: CTA, computed tomography angiography; LCCA, left common carotid artery; LSA, left subclavian artery; TBAD, type B aortic dissection.

had completed false lumen occlusion during follow-up. Amongst 37 cases with immediate ELIa, nine patients became inaccessible. Among the remaining 28, four original ELIa continued; late ELIa were detected in two patients with TBAD, and the false lumens were partially thrombosed in these two cases. The occlusions of chimney stent in LSA were recorded in six (3\%) patients (Table 4). And all the aortic arch bypasses were patency. The details of preoperative CTA as well as follow-up CTA features are listed in Table 5.

\section{Survival Statistics}

The Kaplan-Meier curves for patients with zone 0, zone 1 and zone 2 aortic arch diseases are displayed in Figure 2. The log-rank test indicated no substantial difference among the three survival curves in all-cause death, aorta-specific death or main AEs. Moreover, there was no substantial difference among immediate ELIa and non-immediate ELIa groups as well (Figure 3).

\section{Discussion}

The traditional treatment strategy for aortic arch diseases is open thoracic aortic repair. However, the existing outcomes indicate that 30-day mortality for patients who underwent open surgical reparation is from $2 \%$ to $20 \%$ despite the enhancements in surgical techniques as well as perioperative care. ${ }^{20,21}$ During the past 2 decades, endovascular interventions in descending thoracic aortic disease have become the favorable treatment, which in comparison with the open surgery, leads to decreases in early mortality, morbidity as well as length of hospital stay. ${ }^{22}$

Among several endovascular intervention methods, the chimney technique is applied more and more recently. In 1999, Greenberg et al, used a renal stent parallel to the aortic stent-graft to salvage the renal artery during endovascular treatment of abdominal aortic aneurysm. ${ }^{23}$ In 2007, Criado expansively presented this technique. ${ }^{24}$ This method was named the chimney technique given the parallel association 
Table 2 Details Of The Operation, Aortic Stent-Grafts And Chimney Stents

\begin{tabular}{|c|c|c|c|c|}
\hline & Zone $0(\mathrm{~N}=\mathbf{2 2})$ & Zone I $(\mathrm{N}=13)$ & Zone $2(\mathrm{~N}=|9|)$ & $\begin{array}{l}\text { Total }(\mathrm{N}=226) \text { Or } \\
\text { Mean } \pm \text { SD }\end{array}$ \\
\hline \multicolumn{5}{|l|}{ Details of the operations } \\
\hline Emergency setting & 2 & I & 7 & 10 \\
\hline General anesthesia/Local anesthesia & $22 / 0$ & $0 / 13$ & $0 / 191$ & $22 / 204$ \\
\hline \multicolumn{5}{|l|}{ Preliminary supra-aortic bypasses } \\
\hline RSA-LCCA bypass & I & 0 & 0 & I \\
\hline RSA-LCCA-LSA bypass & 17 & 0 & 0 & 17 \\
\hline RCCA-LCCA-LSA bypass & 3 & 0 & 0 & 3 \\
\hline RCCA-ARSA + RCCA-LCCA-LSA bypasses & I & 0 & 0 & 1 \\
\hline Restrictive bare stent & 2 & I & 13 & 16 \\
\hline Double chimney technique (LCCA + LSA) & 0 & 4 & 0 & 4 \\
\hline Chimney technique use as bailout setting & 0 & 6 & 0 & 6 \\
\hline \multicolumn{5}{|l|}{ Details of aortic stent-grafts } \\
\hline More than one aortic stent-grafts & 2 & 2 & 14 & 18 \\
\hline \multicolumn{5}{|l|}{ Brand of aortic stent-grafts } \\
\hline Valiant (Medtronic, MN, USA) & 3 & 5 & 75 & 83 \\
\hline Zenith TX2 (Cook, IN, USA) & 0 & 0 & 8 & 8 \\
\hline TAG (Gore, AZ, USA) & I & I & 2 & 4 \\
\hline cTAG (Gore, AZ, USA) & 12 & 1 & 39 & 52 \\
\hline Ankura (Lifetech, Shenzhen, China) & 6 & 7 & 53 & 66 \\
\hline Hercules-T (Microport, Shanghai, China) & 3 & 1 & 10 & 14 \\
\hline Aortic (YTH, Beijing, China) & 0 & 0 & 18 & 18 \\
\hline \multicolumn{5}{|l|}{ Details of chimney stent-grafts } \\
\hline Bare/Covered & $\mathrm{II} / \mathrm{I}$ & $17 / 0$ & $165 / 26$ & $193 / 37$ \\
\hline Self-expanding/Balloon-expandable & $\mathrm{II} / \mathrm{I}$ & $13 / 4$ & $154 / 37$ & $178 / 52$ \\
\hline \multicolumn{5}{|l|}{ Brand of chimney stent-grafts } \\
\hline Complete SE (Medtronic, MN, USA) & 0 & 7 & 57 & 64 \\
\hline Express LD (Boston Scientific, MA, USA) & II & 4 & 37 & 52 \\
\hline Wallstent Monorail (Boston Scientific, MA, USA) & 0 & 0 & 1 & I \\
\hline Acculink (Abbott, CA, USA) & 0 & 0 & 1 & I \\
\hline Fluency Plus (Bard Tempe, AZ, USA) & I & 0 & 12 & 13 \\
\hline E.Luminexx (Bard Tempe, AZ, USA) & 0 & 0 & 54 & 54 \\
\hline Maris (Invatec, Brescia, Italy) & 0 & 5 & 15 & 20 \\
\hline Viabahn (Gore, AZ, USA) & 4 & 0 & 13 & 17 \\
\hline Protégé $\mathrm{RX}(\mathrm{ev} 3, \mathrm{MN}, \mathrm{USA})$ & 0 & I & 0 & I \\
\hline Excluder (Gore, AZ, USA) & 6 & 0 & I & 7 \\
\hline
\end{tabular}

Abbreviations: ARSA, aberrant right subclavicular artery; LCCA, left common carotid artery; LSA, left subclavian artery; RCCA, Right common carotid artery; RSA, right subclavian artery.

among the aorta stent-graft and the branch vessel stent. ${ }^{25}$ The Chimney technique has been increasingly utilized in TEVAR. However, there were few studies comparing the outcomes among different zones. To our knowledge, this study represents one first such report documenting the outcome of the chimney technique in aortic arch diseases at a single-center comprising mid-term consequences.

In our study, there was no significant difference among zone 0 , zone 1 and zone 2 in rates of the all-cause death, aorta-specific death or main AEs. This significant outcome has direct implications for clinical application of chimney technique in different zones aortic arch diseases. However, we want to point out that the chimney technique in different zones still has different applicability.

For patients with zone 0 aortic arch diseases, the chimney technique in innominate artery (IA) combined with extra-anatomical bypass was performed in 21 cases in the present study. Besides, for one patient with TBAD 
Table 3 Early- And Mid-Term Outcomes Of Chimney Technique For Aortic Arch Diseases

\begin{tabular}{|c|c|c|c|c|}
\hline & Zone $0(\mathrm{~N}=\mathbf{2 2})$ & Zone I $(\mathrm{N}=13)$ & Zone $2(\mathrm{~N}=191)$ & Total $(\mathrm{N}=\mathbf{2 2 6})$ or Mean \pm SD \\
\hline \multicolumn{5}{|l|}{ Early-term outcomes } \\
\hline Duration of postoperative hospital stay, days & $10 \pm 5$ & $10 \pm 4$ & $7 \pm 5$ & $8 \pm 5$ \\
\hline Immediate type la endoleak & 2 & I & 34 & 37 \\
\hline Puncture site complications & 2 & 0 & 4 & 6 \\
\hline Femoral artery stenosis or occlusion & I & 0 & 3 & 4 \\
\hline Brachial artery pseudoaneurysm & I & 0 & 0 & I \\
\hline Brachial artery local infection & 0 & 0 & 1 & I \\
\hline Major adverse events & 1 & 1 & 7 & 9 \\
\hline All-cause death & I & 0 & 3 & 4 \\
\hline Aortic rupture & 0 & 0 & 1 & I \\
\hline Stroke & I & 0 & 3 & 4 \\
\hline Spinal cord ischemia & 0 & I & 2 & 3 \\
\hline Reintervention & 0 & 0 & 0 & 0 \\
\hline \multicolumn{5}{|l|}{ Mid-term outcomes } \\
\hline Follow-up time, months & $13 \pm 11$ & $40 \pm 10$ & $22 \pm 16$ & $22 \pm 16$ \\
\hline Late type la endoleak & 0 & 0 & 2 & 2 \\
\hline Chimney stent occlusion & 0 & 0 & 6 & 6 \\
\hline Major adverse events & I & 0 & 6 & 7 \\
\hline All-cause death & I & 0 & 4 & 5 \\
\hline Aortic rupture & I & 0 & 2 & 3 \\
\hline Stroke & 0 & 0 & 2 & 2 \\
\hline Spinal cord ischemia & 0 & 0 & 0 & 0 \\
\hline Reintervention & 0 & 0 & 1 & I \\
\hline
\end{tabular}

Table 4 Details Of The Chimney Stent Occlusions

\begin{tabular}{|l|l|l|l|l|l|l|}
\hline No. & $\begin{array}{l}\text { Sex/Age } \\
\text { (yrs) }\end{array}$ & Pathology & $\begin{array}{l}\text { Aortic Stent- } \\
\text { Graft }\end{array}$ & $\begin{array}{l}\text { Brand Of Chimney } \\
\text { Stent }\end{array}$ & $\begin{array}{l}\text { Type Of Chimney } \\
\text { Stent }\end{array}$ & $\begin{array}{l}\text { Time Of Occlusion } \\
\text { (Months) }\end{array}$ \\
\hline I & M/56 & TBAD & Ankura & Maris & Self-expanding/Bare & 16 \\
2 & M/69 & TBAD & Valiant & Complete SE & Self-expanding/Bare & 15 \\
3 & F/60 & IMH & Ankura & E.Luminexx & Self-expanding/Bare & 24 \\
4 & F/52 & PAU & Zenith TX2 & E.Luminexx & Self-expanding/Bare & 8 \\
5 & M/47 & TBAD & cTAG & E.Luminexx & Self-expanding/Bare & 3 \\
6 & M/33 & TBAD & CTAG & Viabahn & Self-expanding/Covered & 6 \\
\hline
\end{tabular}

Abbreviations: IMH, intramural hematoma; PAU, penetrating aortic ulcer; TBAD, type B aortic dissection.

as well as aberrant right subclavian artery (ARSA), the chimney stent was deployed in RCCA and the coils were deployed at the ostia of ARSA and LSA. The greatest advantage of the IA chimney technique is creation of a landing zone in ascending aorta without sternotomy or cardiopulmonary bypass. ${ }^{26}$ Therefore, chimney technique in zone 0 is of significance in clinical practice. However, it should be noted that the IA chimney stent acts as the only inflow vessel to the cerebral circulation. If the chimney stent is fractured, stenosed, occluded or thrombosed, it may lead to a life-threatening complication. Completed debranching is another option for these zone 0 patients, which can be performed by a side-biting clamp of the ascending aorta. But it has a potential risk of causing damage to ascending aorta and might result in type A aortic dissection. In addition, the cost of debranching is higher than IA chimney technique. Currently, there are few studies comparing the safety and efficacy between completed debranching and the IA chimney technique for the zone 0 aortic arch pathologies. Due to the lack of evidence, we are not able to draw the final conclusion about which technique is much better. For the patients with 
Table 5 Details Of Preoperative CTA And Follow-Up CTA

\begin{tabular}{|c|c|c|c|c|}
\hline & Zone $0(\mathrm{~N}=22)$ & Zone I $(\mathrm{N}=13)$ & Zone $2(\mathrm{~N}=191)$ & Total $(\mathrm{N}=226)$ Or Mean \pm SD \\
\hline \multicolumn{5}{|l|}{ Preoperative CTA features } \\
\hline TBAD & 10 & 12 & 163 & 185 \\
\hline Maximum diameter of aorta, $\mathrm{mm}$ & $37.8 \pm 3.7$ & $38.5 \pm 2.5$ & $38.1 \pm 2.8$ & $38.1 \pm 2.8$ \\
\hline Size of primary entry tear, $\mathrm{mm}$ & $10.3 \pm 2.6$ & $11.0 \pm 2.2$ & $10.3 \pm 2.8$ & $10.3 \pm 2.7$ \\
\hline \multicolumn{5}{|l|}{ Blood supply of visceral arteries } \\
\hline Celiac artery (TL/FL/TF) & $2 / 6 / 2$ & $10 / 1 / 1$ & $73 / 46 / 44$ & $85 / 53 / 47$ \\
\hline Superior mesenteric artery (TL/FL/TF) & $6 / 0 / 4$ & $5 / 4 / 3$ & $7|/ 4| / 5 I$ & $82 / 45 / 58$ \\
\hline Left renal artery (TL/FL/TF) & $2 / 2 / 6$ & $3 / 3 / 6$ & $61 / 45 / 57$ & $66 / 50 / 69$ \\
\hline Right renal artery (TL/FL/TF) & $3 / 4 / 3$ & $6 / 3 / 3$ & $68 / 55 / 40$ & $77 / 62 / 46$ \\
\hline \multicolumn{5}{|l|}{ False Lumen Status } \\
\hline Completely thrombosed & 2 & 1 & 13 & 16 \\
\hline Partially thrombosed & 1 & 2 & 38 & 41 \\
\hline Patent & 7 & 9 & 112 & 128 \\
\hline Aneurysm & 11 & 1 & 11 & 23 \\
\hline Maximum diameter of aorta, $\mathrm{mm}$ & $62.0 \pm 6.6$ & 62.4 & $58.9 \pm 3.5$ & $60.5 \pm 5.3$ \\
\hline Mural thrombus & 3 & 0 & 7 & 10 \\
\hline Other pathologise & 1 & 0 & 17 & 18 \\
\hline \multicolumn{5}{|l|}{ Domination of vertebral artery } \\
\hline Left dominant & 9 & 4 & 79 & 92 \\
\hline Right dominant & 7 & 5 & 77 & 89 \\
\hline Equality dominant & 6 & 4 & 35 & 45 \\
\hline Follow-up CTA features & & & & 173 \\
\hline TBAD & 10 & 6 & 123 & 139 \\
\hline Maximum diameter of aorta, $\mathrm{mm}$ & $36.1 \pm 3.3$ & $37.2 \pm 3.5$ & $37.0 \pm 2.8$ & $36.9 \pm 2.9$ \\
\hline Original type la endoleak persisted & 0 & 0 & 4 & 4 \\
\hline Late type la endoleak & 0 & 0 & 2 & 2 \\
\hline Aneurysm & 10 & 1 & 9 & 20 \\
\hline Maximum diameter of aorta, $\mathrm{mm}$ & $57.7 \pm 5.2$ & 61.2 & $56.3 \pm 4.9$ & $57.2 \pm 4.9$ \\
\hline Sac regression & 3 & 0 & 2 & 5 \\
\hline Other pathologies & 1 & 0 & 13 & 14 \\
\hline
\end{tabular}

Abbreviations: FL, false lumen; TF, true lumen and false lumen; TL, true lumen; TBAD, type B aortic dissection.

proximal landing in zone 0 , traditional open surgery is the first choice in our center. However, this procedure is associated with high incidences of morbidity and mortality because traditional open surgery still requires sternotomy, hypothermic cardiac arrest, and cardiopulmonary bypass. So only for the patients with advanced age and/or multiple coexisting diseases, we would carefully use chimney stent inIA for the treatment.

For patients with zone 1 aortic arch diseases, we prefer to conduct the hybrid procedure (supra-arch bypasses and TEVAR) instead of double chimney stents in LCCA and LSA. Compared with the single chimney technique, the double chimney technique produces a wider gutter, especially when the double stents are close to each other, which can encourage type Ia endoleak development. The chimney technique was used only in the cases of accidental coverage of LCCA (Figure 2) or the patients rejected to undergo the hybrid procedure. Coverage of the LSA is usually unavoidable in zone 1 cases. If LSA restoration is essential, double chimney technique, LCCA-LSA bypass, or in situ stent-graft fenestration technique might be considered. Compared to the single chimney technique, the double chimney technique creates a broader gutter, which can encourage ELIa development. In this study, 1 of 4 patients undergoing the double chimney technique had asymptomatic ELIa.

For patients with zone 2 aortic arch diseases, chimney technique can be performed under local anesthesia. Whether it is needed to reconstruct LSA or not is debatable. There were increasing evidences suggesting a greater risk of left upper-extremity ischemia as well as vertebrobasilar ischemia after LSA coverage that was related to an 


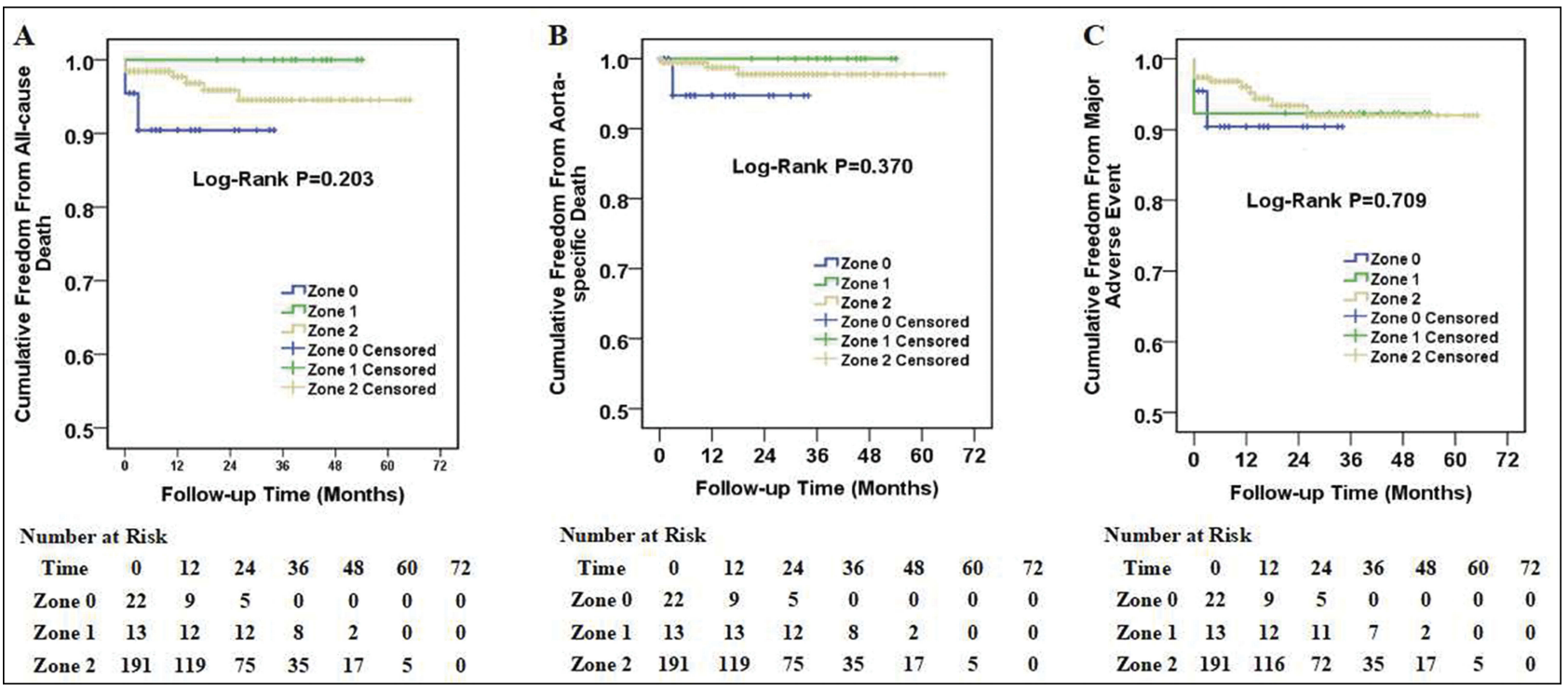

Figure 2 Kaplan-Meier curves among patients with zone 0, zone I and zone 2 aortic arch diseases. Cumulative all-cause death curves (A), aorta-specific death curves (B) and major adverse event curves $(\mathbf{C})$ in patients with zone 0 , zone I and zone 2 aortic arch diseases. The number of patients at risk at each year was listed in the bottom of the figure.

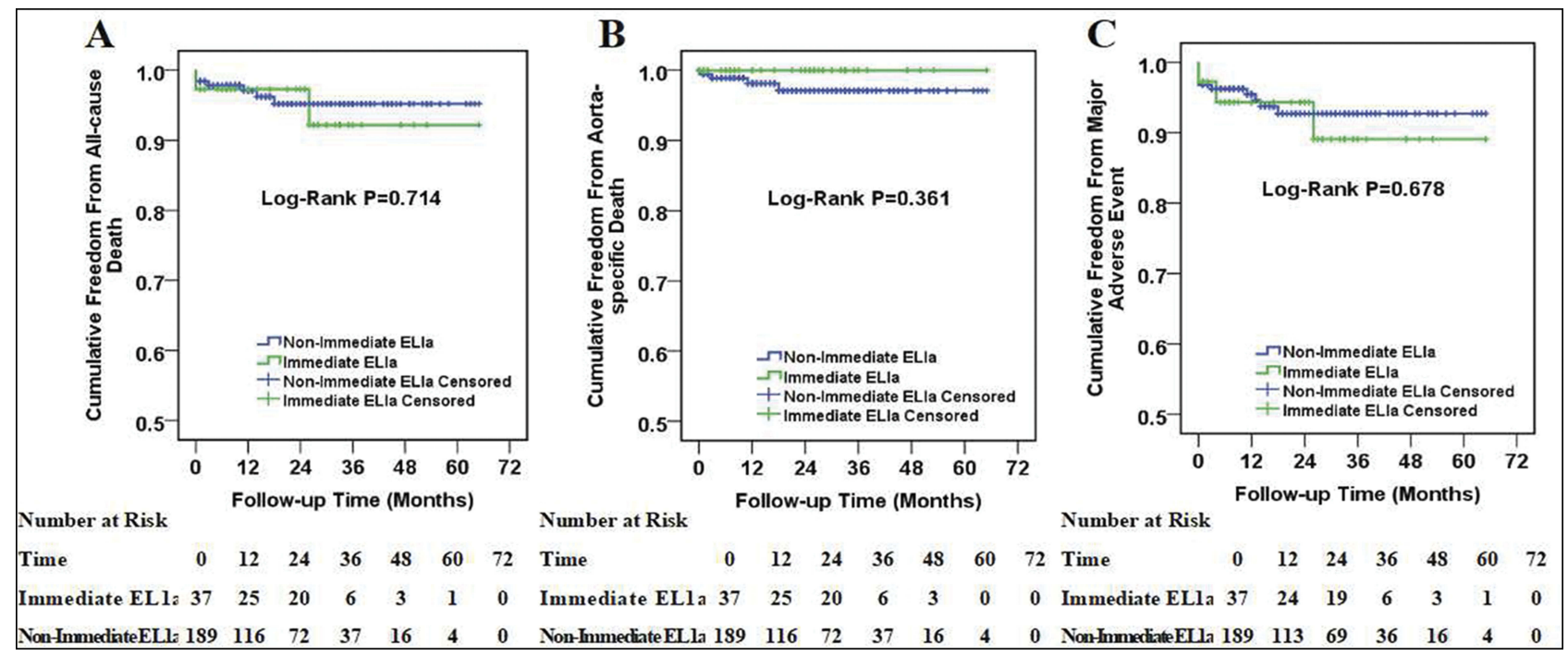

Figure 3 Kaplan-Meier curves among patients with immediate type la endoleak and non-immediate type la endoleak. Cumulative all-cause death curves (A), aorta-specific death curves (B) and major adverse event curves (C) in patients with immediate type la endoleak and non-immediate type la endoleak. The number of patients at risk at each year was listed in the bottom of the figure.

augmented risk of stroke. ${ }^{27}$ Therefore, revascularization of the LSA would have to be done in all elective cases routinely as recommended by the Society for Vascular Surgery practice guidelines. ${ }^{28}$ However, some experts believe that it is safe to cover LSA without revascularization during TEVAR if the circle of Willis is normal. Given that most of the patients with aortic diseases did not receive cranial CTA to assess the integrity of Willis circle, so we routinely used the chimney technique to restructure
LSA in zone 2 aortic arch diseases. If the anatomy was not appropriate, the LCCA-LSA bypass was done when the patient had unfinished Willis circle, dominant LSA or ARSA. Based on our data, compared to the hybrid technique, the chimney technique is more beneficial with regard to promptness, decreased invasiveness as well as enhanced safety.

One problem with the chimney technique is the possibility of ELIa. In our study, 37 (16\%) immediate ELIa were 
reported. While there was not any substantial difference among immediate ELIa as well as non-immediate ELIa groups about the all-cause death, aorta-specific death or key AEs, consistent with previously published studies, ${ }^{13,29}$ efforts shall be taken to minimize ELIa. Several methods have been described in literature to reduce the occurrence of ELIa. In theory, a covered stent may be beneficial as it can reduce the blood flow via the mesh of the bare stent into the gutter. Besides, to stimulate thrombosis in the gutter, Wang et al, suggested at least $2 \mathrm{~cm}$ of overlapping among the chimney stent and aortic stent-graft. ${ }^{12}$ Moreover, sufficient oversizing of the aortic stent-graft may reduce the risk of ELIa by narrowing the gutter. It has been reported that the gutter ought to be made extremely far away from entry tear for patients with TBAD. ${ }^{29}$ The kissing balloon technique has to be utilized with proper caution because it might lead to retrograde type A aortic dissection. Another favorable method to handle the ELIa is to specifically catheterize and embolize the gutter by coils. ${ }^{30}$ In our center, for patients with chimney stent, the diameters of aortic stent-grafts were usually oversized by $10-15 \%$ in TBAD and $15-20 \%$ in aneurysm and the diameters of chimney stents were oversized by $10-20 \%$. Moreover, the direction of the chimney stent would be decided by the relative position of the proximal tear in patients with TBAD. When the tear was located in anterior segment, the chimney graft should be deployed behind the aortic stent-graft, close to the posterior wall of thoracic aorta, whereas chimney graft deployed in front of the aortic stent-grafts when the tear was located in posterior segment.

The structure for the chimney graft is still a debatable subject. Both bare and covered stents have been applied, but the consensus about which is more suitable has not been reached. ${ }^{12,13,29,31}$ In our center, we hold the opinion that if the tear near the ostium of supra-arch branch, or supra-arch branch dissection, covered stent may be more useful to form a blind channel to reduce the threat of ELIa. Nevertheless, covered stents needed to be inserted by brachial artery due to their large delivery system; while, with thin delivery system, the bare stent can be inserted via percutaneous radial artery access. $22 \%$ of patients in our cohort did not have sufficient imaging follow-up, which made it unreliable to judge the results among covered and bare stent. Further studies are needed to guide the reasonable choice for bare chimney stent or cover chimney stent.

The patency of chimney stent is also an important subject. It has been reported that the primary patency of the chimney stent in aortic arch lesions was 99\% (361/364). ${ }^{3}$
Likewise, the outcomes from a European multicenter registry study indicated that the primary patency of the chimney stents was $98 \%$ (100/102). ${ }^{4}$ Two patients with occluded self-expandable covered stents in the LSA did not have any symptoms. In our study, self-expandable chimney stent occlusion in LSA was detected in six patients during follow-up. Because there was no vertebral basilar artery ischemia or left upper limb ischemia, they were closely monitored without reintervention. We believe that the speculative cause was that the self-expanding stent reduces the radial force. Since the obstructions were only in selfexpanding chimney stents, balloon-expandable chimney stents might be a better rational choice. This has to be validated by forthcoming researches.

The results from the current study reveal that the chimney technique is effective and safe for aortic arch diseases in different zones. The permanency of chimney stent needed to be assessed and immediate type Ia endoleak should be concerned. Nonetheless, there are several limitations of this study. Firstly, it was an observational as well as retrospective study, and the results signified the experience acquired at a single institute. Secondly, there were $22 \%$ of patients without sufficient imaging followup, so we were not able to evaluate the chimney patency as well as the endoleaks precisely. Finally, the number of patients in zones 0 or 1 is less than that in zone 2, and the follow-up in zone 0 was relatively short. Hence, more patients have to be evaluated along with the necessity of the long-term follow-up to acquire a complete and precise conclusion.

\section{Funding}

The study was supported by the National Natural Science Foundation of China (81670429, 91839103), International Joint Laboratory for Arteriosclerotic Disease Research of Hunan Province (2018WK4031) and "Double First-Class" project for innovative Group of Basic Medicine, University of South China (2019SYL02).

\section{Disclosure}

The authors report no conflicts of interest in this work.

\section{References}

1. Erbel R, Aboyans V, Boileau C, et al. ESC guidelines on the diagnosis and treatment of aortic diseases: document covering acute and chronic aortic diseases of the thoracic and abdominal aorta of the adult. The Task Force for the Diagnosis and Treatment of Aortic Diseases of the European Society of Cardiology (ESC). Eur Heart J. 2014;35 (41):2873-2926. doi:10.1093/eurheartj/ehu281 
2. Zhu Y, Guo W, Liu X, Jia X, Xiong J, Wang L. The single-centre experience of the supra-arch chimney technique in endovascular repair of type B aortic dissections. Eur J Vasc Endovasc Surg. 2013;45(6):633-638. doi:10.1016/j.ejvs.2013.02.016

3. Lindblad B, Bin JA, Holst J, Malina M. Chimney grafts in aortic stent grafting: hazardous or useful technique? Systematic review of current data. Eur J Vasc Endovasc Surg. 2015;50(6):722-731. doi:10.1016/j. ejvs.2015.07.038

4. Bosiers MJ, Donas KP, Mangialardi N, et al. European multicenter registry for the performance of the Chimney/Snorkel technique in the treatment of aortic arch pathologic conditions. Ann Thorac Surg. 2016;101(6):2224-2230. doi:10.1016/j.athoracsur.2015.10.112

5. Benrashid E, Wang H, Keenan JE, et al. Evolving practice pattern changes and outcomes in the era of hybrid aortic arch repair. $J$ Vasc Surg. 2016;63(2):323-331. doi:10.1016/j.jvs.2015.09.004

6. Tsilimparis N, Debus ES, von Kodolitsch Y, et al. Branched versus fenestrated endografts for endovascular repair of aortic arch lesions. $J$ Vasc Surg. 2016;64(3):592-599. doi:10.1016/j.jvs.2016.03.410

7. Spanos K, Tsilimparis N, Rohlffs F, et al. Total endovascular arch repair is the procedure of the future. Part I. J Cardiovasc Surg (Torino). 2018;59(4):559-571.

8. Cao P, De Rango P, Czerny M, et al. Systematic review of clinical outcomes in hybrid procedures for aortic arch dissections and other arch diseases. J Thorac Cardiovasc Surg. 2012;144(6):1286-1301. doi:10.1016/j.jtcvs.2012.06.013

9. Hiraoka A, Chikazawa G, Tamura K, Totsugawa T, Sakaguchi T, Yoshitaka H. Clinical outcomes of different approaches to aortic arch disease. J Vasc Surg. 2015;61(1):88-95. doi:10.1016/j.jvs.2014.06.121

10. Hongku K, Dias N, Sonesson B, Resch T. Techniques for aortic arch endovascular repair. J Cardiovasc Surg (Torino). 2016;57(3):421-436.

11. Criado FJ, Barnatan MF, Rizk Y, Clark NS, Wang CF. Technical strategies to expand stent-graft applicability in the aortic arch and proximal descending thoracic aorta. J Endovasc Ther. 2002;9(Suppl 2):I32-I38. doi:10.1177/15266028020090S206

12. Wang T, Shu C, Li M, et al. Thoracic endovascular aortic repair with single/double chimney technique for aortic arch pathologies. J Endovasc Ther. 2017;24(3):383-393. doi:10.1177/1526602817698702

13. Zou J, Jiao Y, Zhang X, Jiang J, Yang H, Ma H. Early- and mid-term results of the chimney technique in the repair of aortic arch pathologies. Cardiovasc Intervent Radiol. 2016;39(11):1550-1556. doi:10.1007/s00270-016-1439-6

14. Li Y, Hu Z, Wang J, Zhang Y, Chen Z, Zhang H. Endovascular chimney technique for aortic arch pathologies treatment: a systematic review and meta-analysis. Ann Vasc Surg. 2018;47:305-315. doi:10.1016/j.avsg.2017.09.006

15. Ahmad W, Mylonas S, Majd P, Brunkwall JS. A current systematic evaluation and meta-analysis of chimney graft technology in aortic arch diseases. J Vasc Surg. 2017;66(5):1602-1610. doi:10.1016/j. jvs.2017.06.100

16. Ni ZH, Luo JF, Huang WH, et al. Totally percutaneous thoracic endovascular aortic repair with the preclosing technique: a casecontrol study. Chin Med J (Engl). 2011;124(6):851-855.

17. Chen J, Huang W, Luo S, Yang D, Xu Z, Luo J. Application of rapid artificial cardiac pacing in thoracic endovascular aortic repair in aged patients. Clin Interv Aging. 2014;973-978.
18. Mitchell RS, Ishimaru S, Ehrlich MP, et al. First International Summit on Thoracic Aortic Endografting: roundtable on thoracic aortic dissection as an indication for endografting. J Endovasc Ther. 2002;9(Suppl 2):I98-I105. doi:10.1177/15266028020090S216

19. Fillinger MF, Greenberg RK, McKinsey JF, Chaikof EL. Reporting standards for thoracic endovascular aortic repair (TEVAR). J Vasc Surg. 2010;52(4):1022-1033. doi:10.1016/j.jvs.2010.07.008

20. Maurel B, Sobocinski J, Spear R, et al. Current and future perspectives in the repair of aneurysms involving the aortic arch. $J$ Cardiovasc Surg (Torino). 2015;56(2):197-215.

21. Coselli JS, Green SY. Aortic arch repair today: open repair is best for most arch lesions. J Cardiovasc Surg (Torino). 2015;56(4):531-546.

22. Cheng D, Martin J, Shennib H, et al. Endovascular aortic repair versus open surgical repair for descending thoracic aortic disease a systematic review and meta-analysis of comparative studies. $J$ Am Coll Cardiol. 2010;55(10):986-1001. doi:10.1016/j.jacc. 2009.11.047

23. Greenberg RK, Clair D, Srivastava S, et al. Should patients with challenging anatomy be offered endovascular aneurysm repair? $J$ Vasc Surg. 2003;38(5):990-996. doi:10.1016/s0741-5214(03)00896-6

24. Criado FJ. A percutaneous technique for preservation of arch branch patency during thoracic endovascular aortic repair (TEVAR): retrograde catheterization and stenting. J Endovasc Ther. 2007;14(1):5458. doi:10.1583/06-2010.1

25. Criado FJ. Chimney grafts and bare stents: aortic branch preservation revisited. J Endovasc Ther. 2007;14(6):823-824. doi:10.1583/072247.1

26. Shirakawa Y, Kuratani T, Shimamura K, et al. The efficacy and shortterm results of hybrid thoracic endovascular repair into the ascending aorta for aortic arch pathologies. Eur J Cardiothorac Surg. 2014;45 (2):298-304, 304. doi:10.1093/ejcts/ezt391

27. Rizvi AZ, Murad MH, Fairman RM, Erwin PJ, Montori VM. The effect of left subclavian artery coverage on morbidity and mortality in patients undergoing endovascular thoracic aortic interventions: a systematic review and meta-analysis. J Vasc Surg. 2009;50 (5):1159-1169. doi:10.1016/j.jvs.2009.09.002

28. Matsumura JS, Lee WA, Mitchell RS, et al. The Society for Vascular Surgery Practice Guidelines: management of the left subclavian artery with thoracic endovascular aortic repair. J Vasc Surg. 2009;50(5):1155-1158. doi:10.1016/j.jvs.2009.08.090

29. Huang C, Tang H, Qiao T, Liu C, Zhou M. Early results of chimney technique for type $\mathrm{b}$ aortic dissections extending to the aortic arch. Cardiovasc Intervent Radiol. 2016;39(1):28-35. doi:10.1007/s00270015-1145-9

30. Mangialardi N, Serrao E, Kasemi H, Alberti V, Fazzini S, Ronchey S. Chimney technique for aortic arch pathologies: an 11-year single-center experience. J Endovasc Ther. 2014;21(2):312-323. doi:10.1583/134526MR. 1

31. Xue Y, Sun L, Zheng J, et al. The chimney technique for preserving the left subclavian artery in thoracic endovascular aortic repair. Eur $J$ Cardiothorac Surg. 2015;47(4):623-629. doi:10.1093/ejcts/ezu266 


\section{Publish your work in this journal}

Clinical Interventions in Aging is an international, peer-reviewed journal focusing on evidence-based reports on the value or lack thereof of treatments intended to prevent or delay the onset of maladaptive correlates of aging in human beings. This journal is indexed on PubMed Central, MedLine, CAS, Scopus and the Elsevier
Bibliographic databases. The manuscript management system is completely online and includes a very quick and fair peer-review system, which is all easy to use. Visit http://www.dovepress.com/ testimonials.php to read real quotes from published authors. 